\title{
Innovation and Productivity Facilitate the Efficiency of Human Resources
}

\author{
Pirhossein Koulivand ${ }^{*}$
}

Shefa Neuroscience Research Center, Khatam Alanbia Hospital, Tehran, Iran

\section{A BSTRACT}

Introduction: Today's management is aware of the fact that even with the implementation of total quality management and reengineering, organizations will not be able to systematically satisfy the conflicting goals. Comprehensive productivity management philosophy not only consists of management principles by objectives, total quality management and reengineering, but relies on the most important and most fundamental goal of societies, such as improving the material and spiritual welfare. Conclusion: Therefore, the goal of productivity improvements is to maximize the use of manpower resources and facilities to the scientific methods, reduce production costs, expand markets, increase job opportunities, increase salaries as well as to improve the living standards for the benefit of employees, managers, and consumers. Finally improving productivity results in increasing employment opportunities.

Key words:

1. Goals

2. Economics

3. Employment

*Corresponding Author: Pirhossein Koulivand

E-mail: peirhossein@yahoo.com 


\section{نو آورى و بهرهورى، راه تشاى بازدهى منابع انسانى}

\section{"يير حسين كوليوند"}

مركز تحقيقات علوم اعصاب شفا، بيمارستان خاتمالانبياء، تهران، ايران

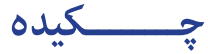

مقدمه: مديريت امروزه از اين واقعيت كه حتى با اجراى مديريت كيفيت و مهندسى مجداد، سازمانها

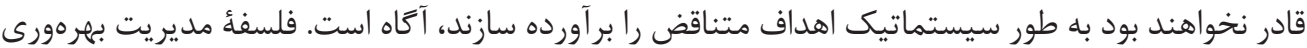

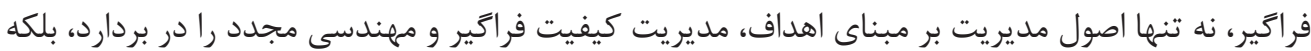

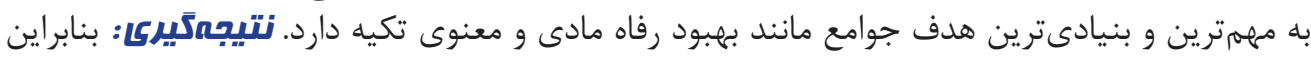

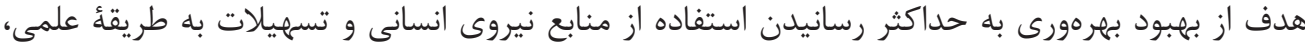

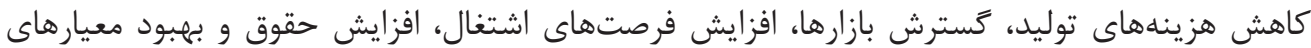

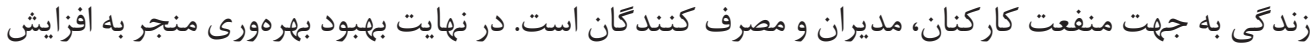
فرصتهاى اشتغال مىشود.

كليد وازهها:

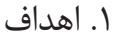

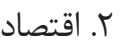

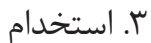

$$
\text { * نويسنده مسئول: ييرحسين كوليوند }
$$
آدرس الكترونيكى: peirhossein@yahoo.com 


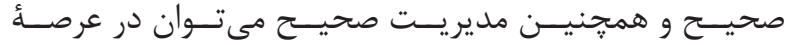

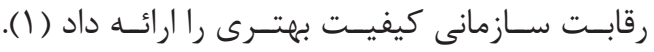

سابقه و تاريخجهة بهر وورى

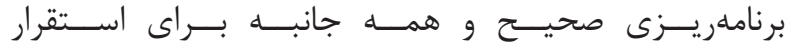

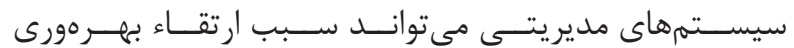

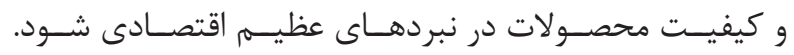

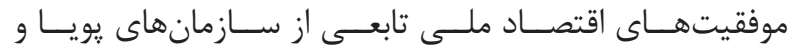

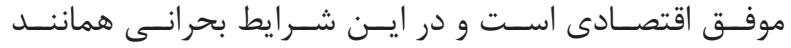

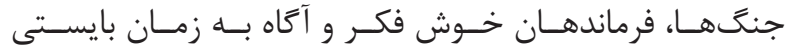

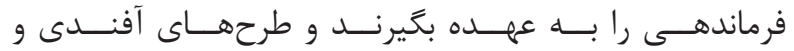

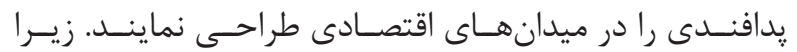

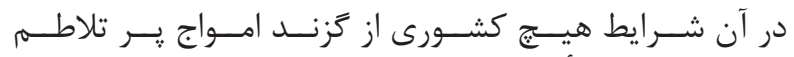

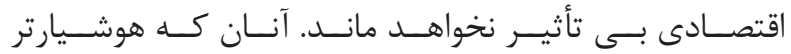

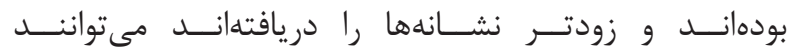

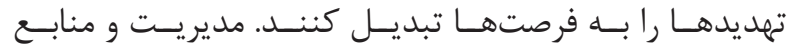

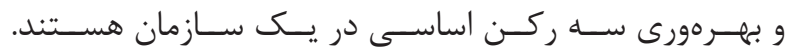

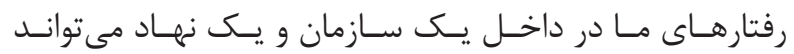

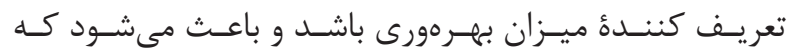

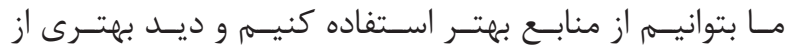

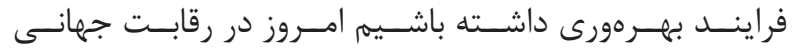

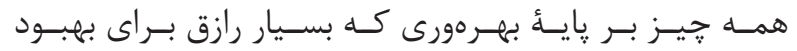

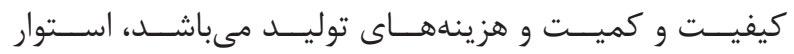

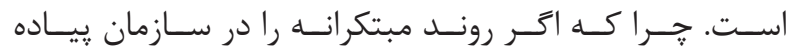

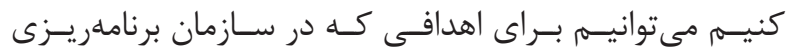

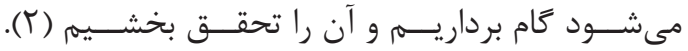

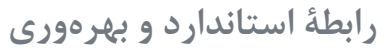

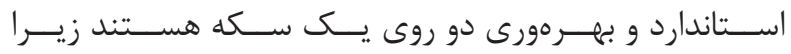

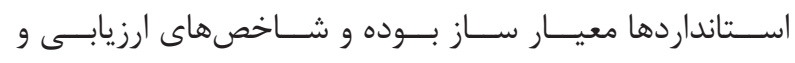

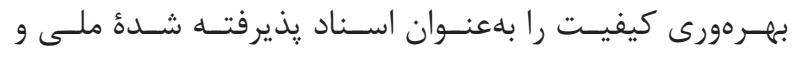

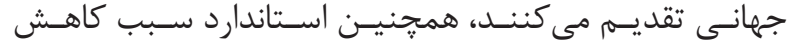

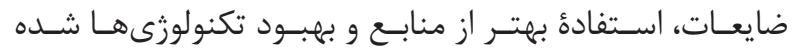

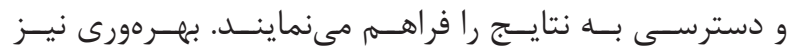

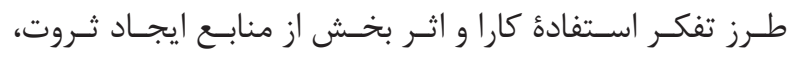

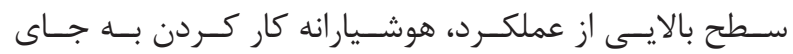

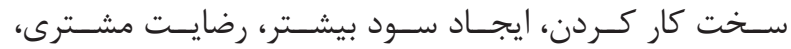

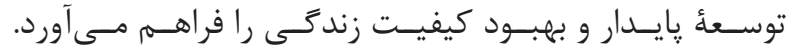

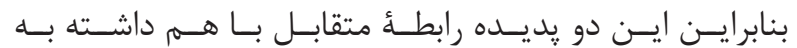

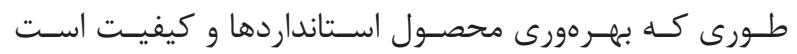

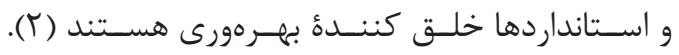

مديريت خرد و بمهرورى

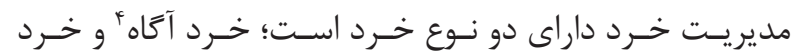

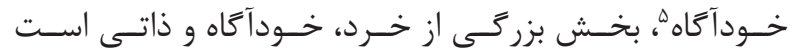

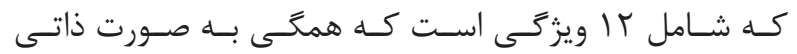

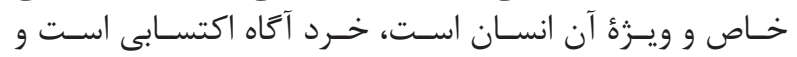

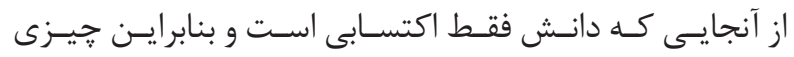

${ }^{1}$ Productivity

${ }^{2}$ Quesnay

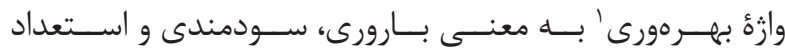

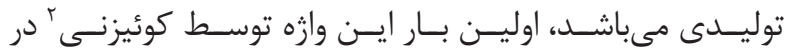

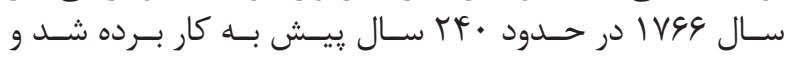

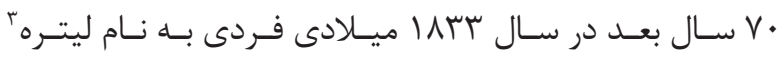

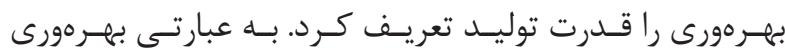

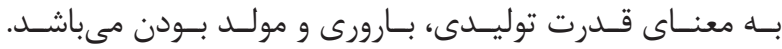

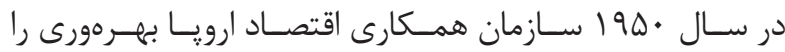

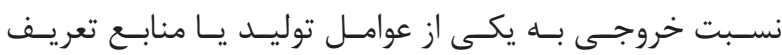

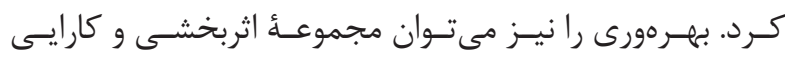

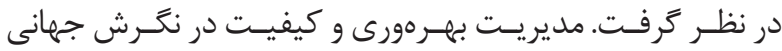

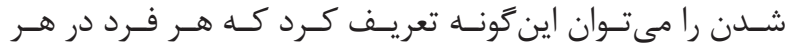

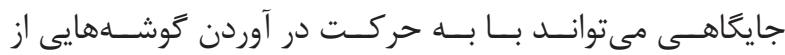

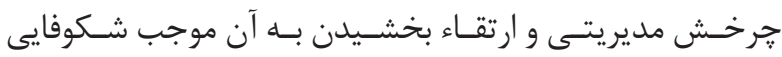

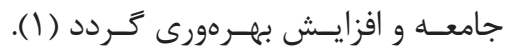
ترويج بهر هورى و كيفيت

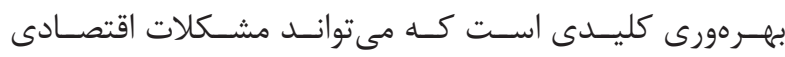

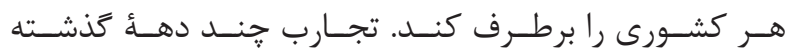

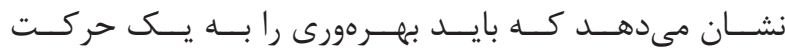

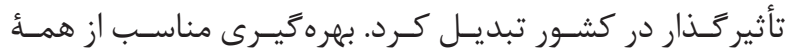

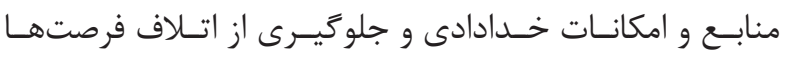

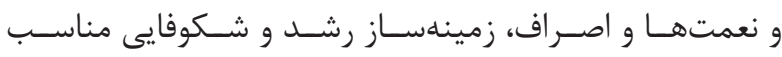

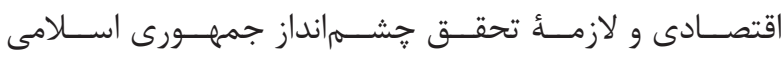

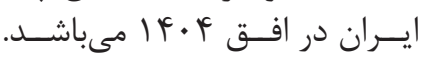

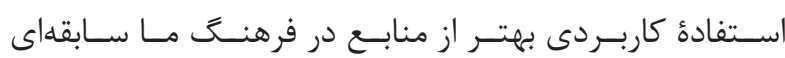

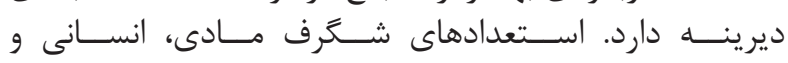

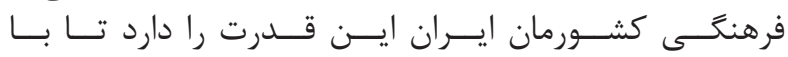

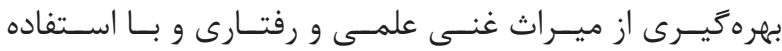

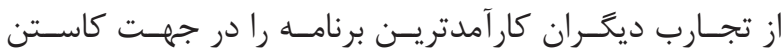

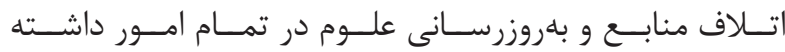

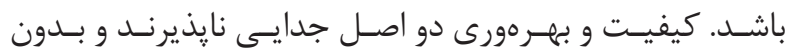

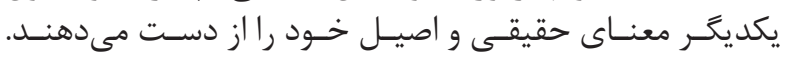

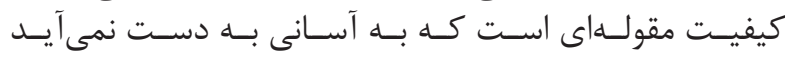

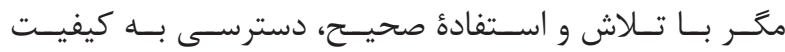

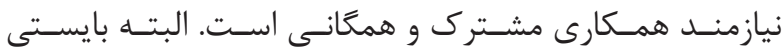

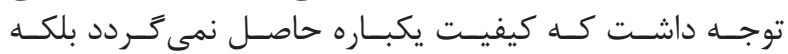

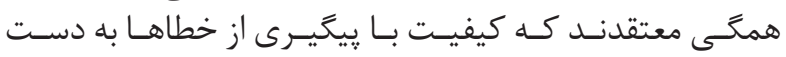

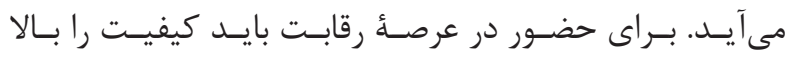

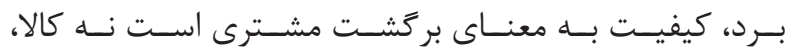

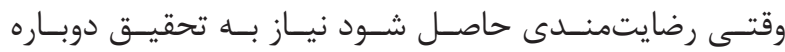

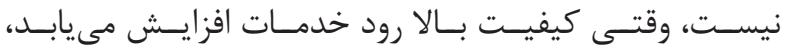

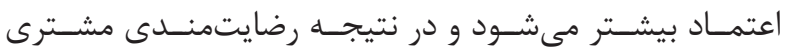

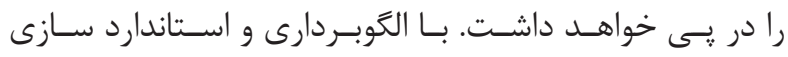

${ }^{4}$ Explicit

${ }^{5}$ Tacit 


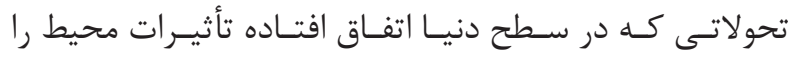

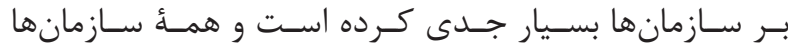

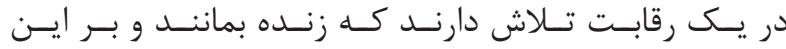

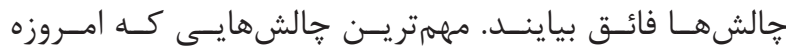

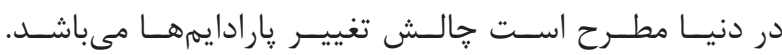

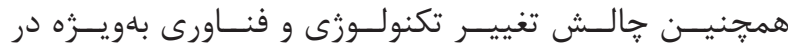

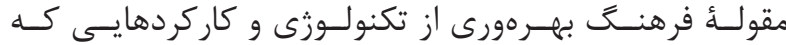

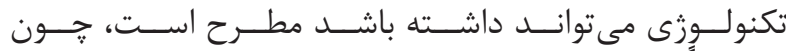

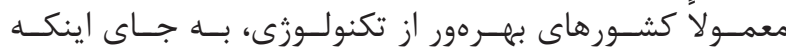

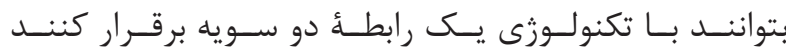

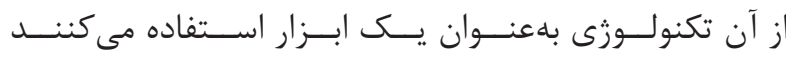

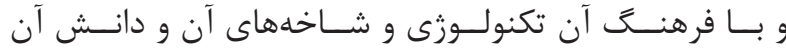

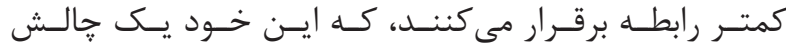

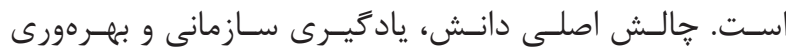

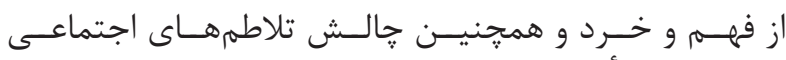

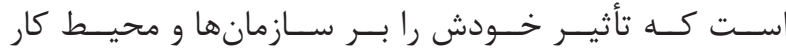

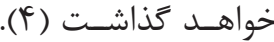

نو آورى (منابع انسانى -مديريت انسانى)

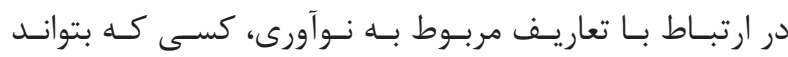

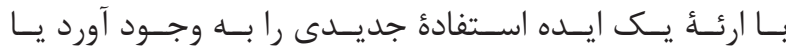

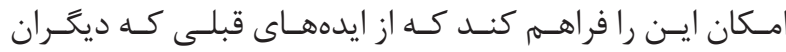

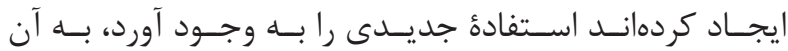

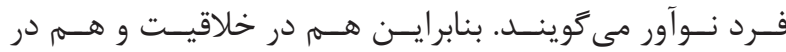

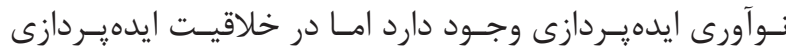

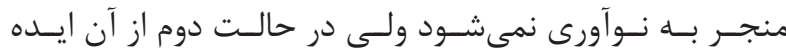

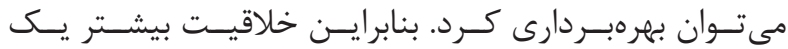

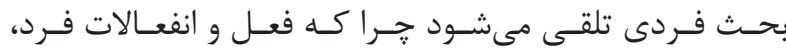

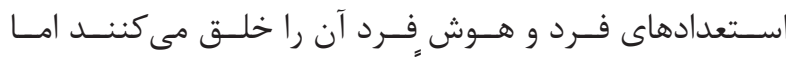

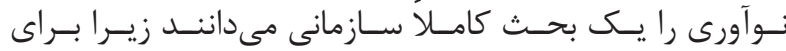

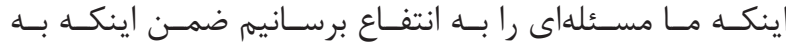

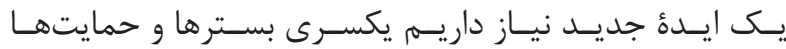

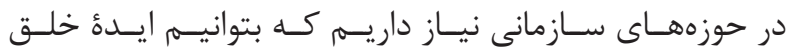

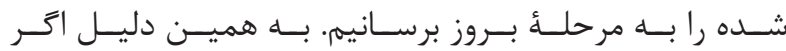

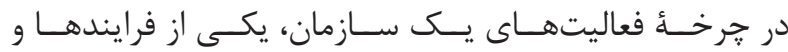

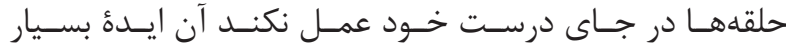

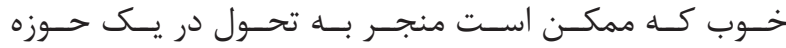

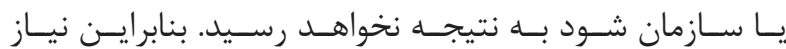

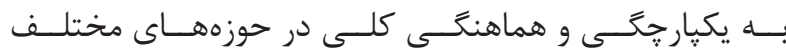

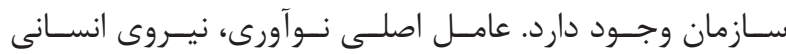

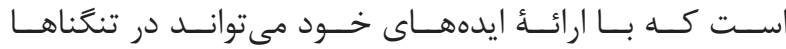

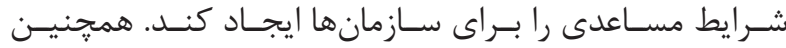

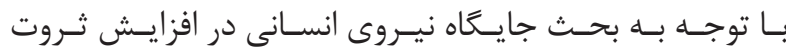

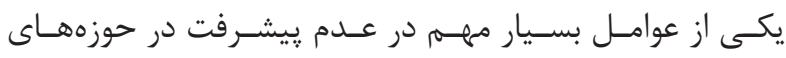

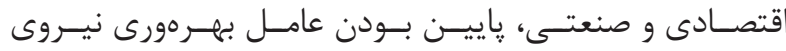

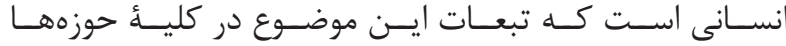

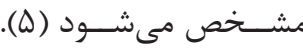

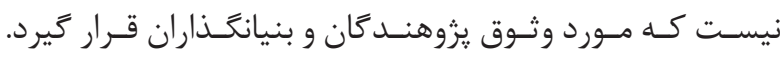

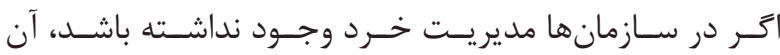

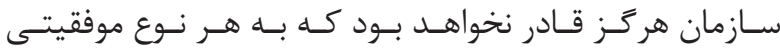

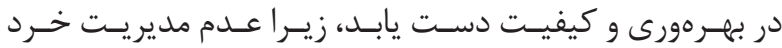

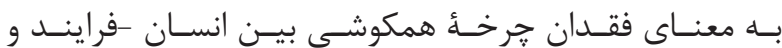

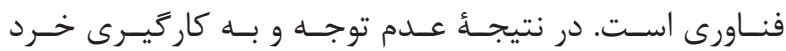

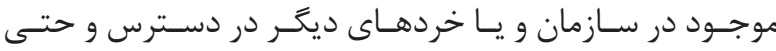

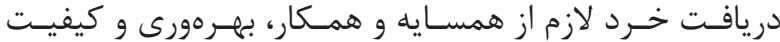

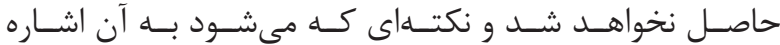

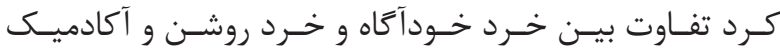

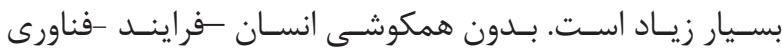

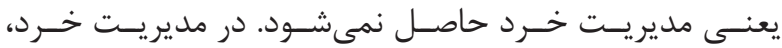

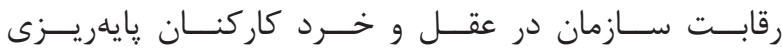

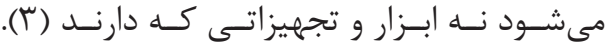

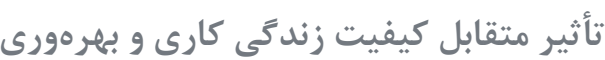

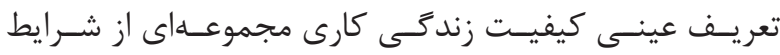

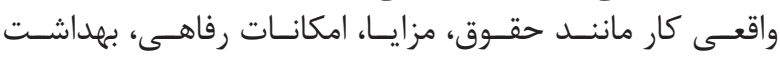

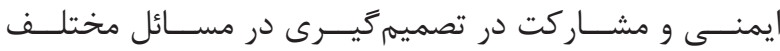

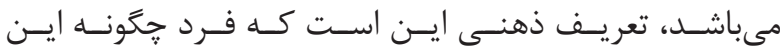

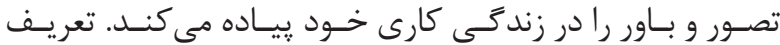

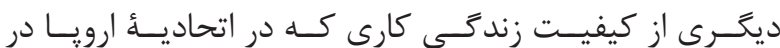

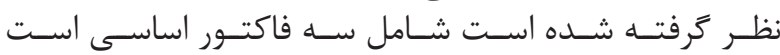

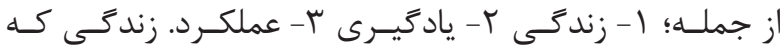

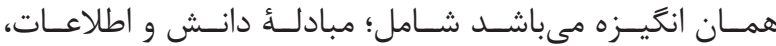

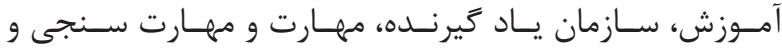

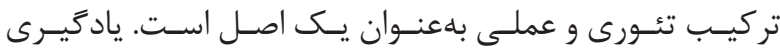

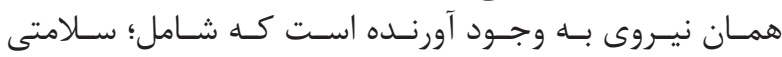

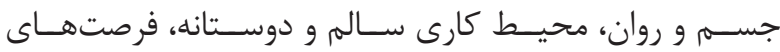

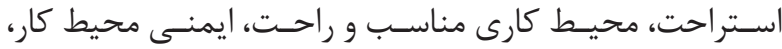

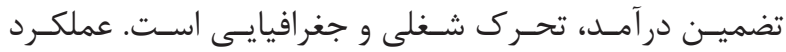

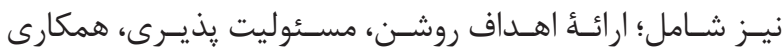

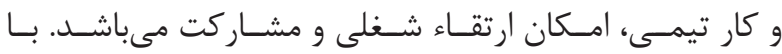

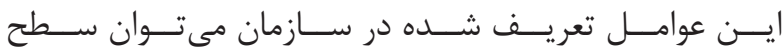

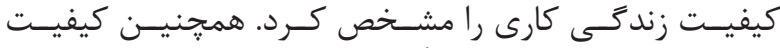

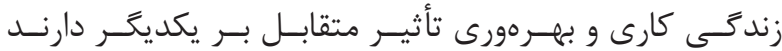

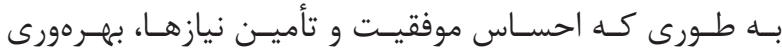

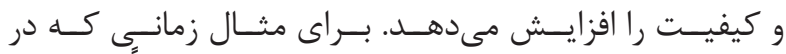

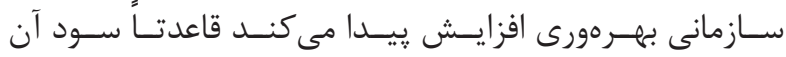

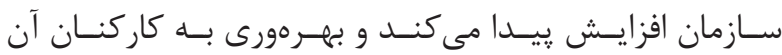

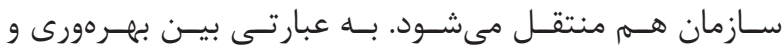

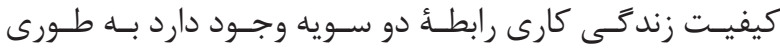

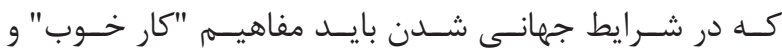

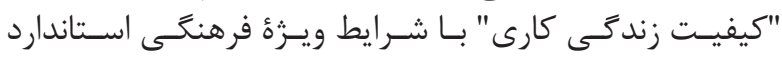

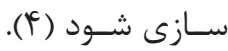

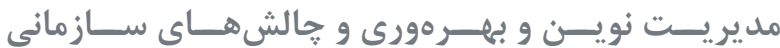

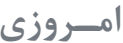




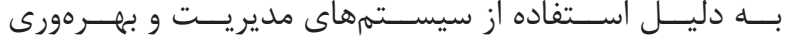

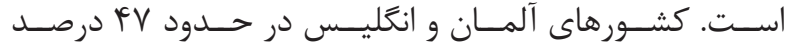

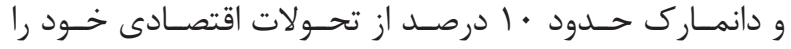

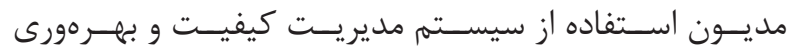

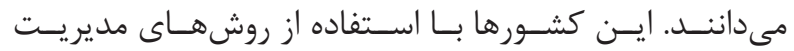

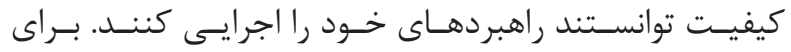

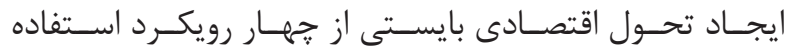

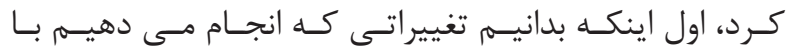

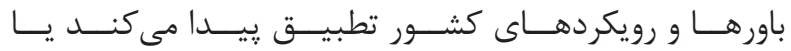

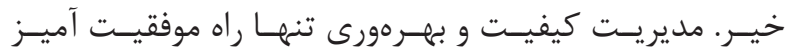

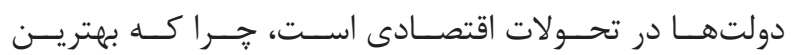

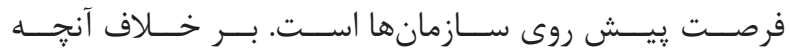

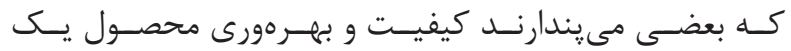

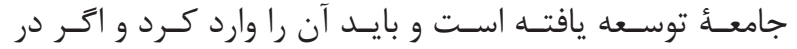

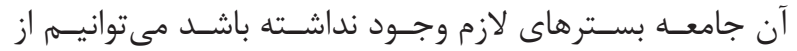

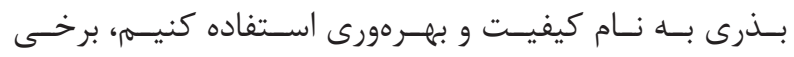

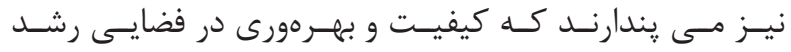

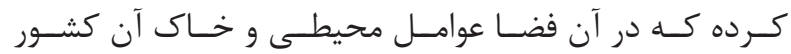

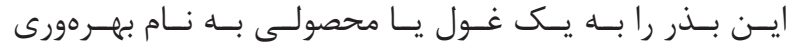

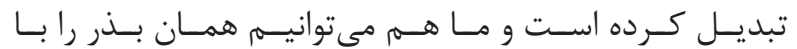

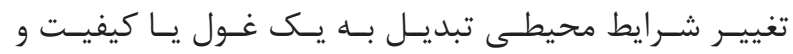

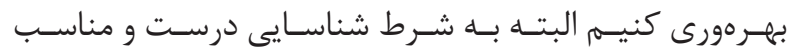

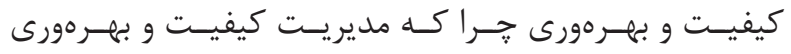

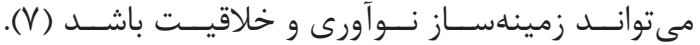

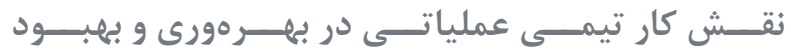

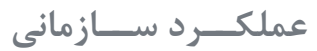
كار تيمـى يكـى از ضرورتهــــ دنيـاى كسـب و كار فعلـى

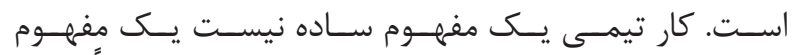

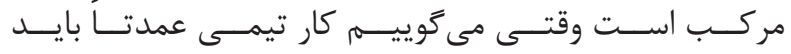

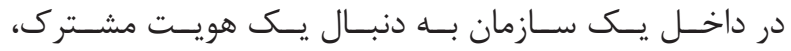

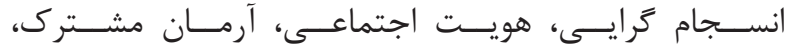

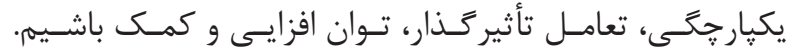

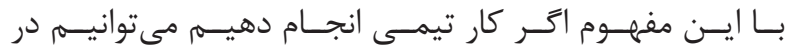

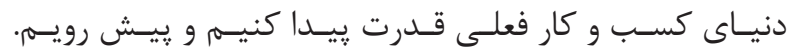

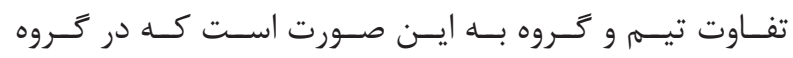

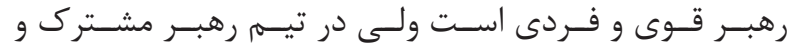

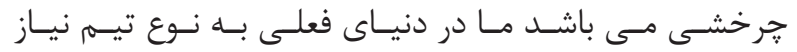

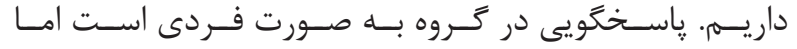

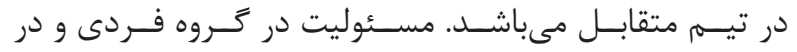

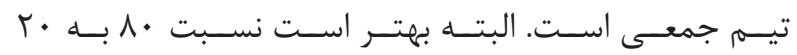

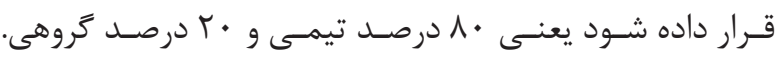

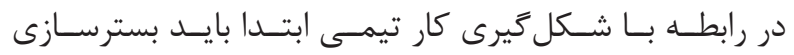

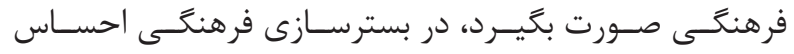

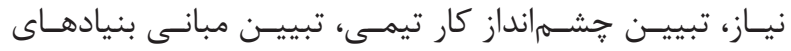

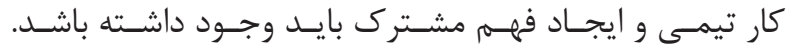

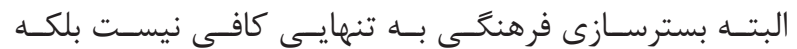

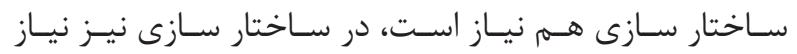

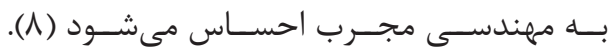

راهبردهاى رهبرى در اثربخشى بهروروى

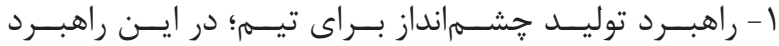

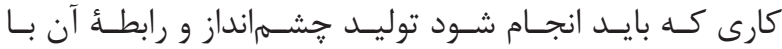

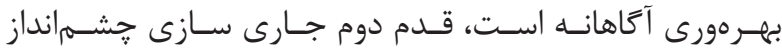

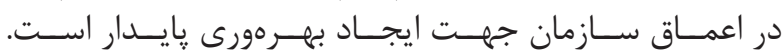

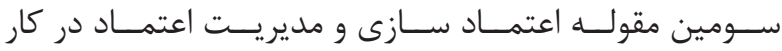

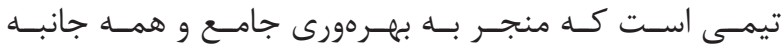

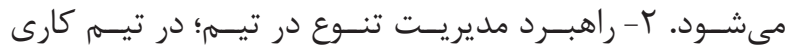

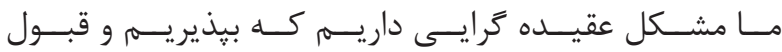

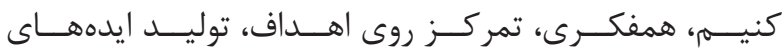

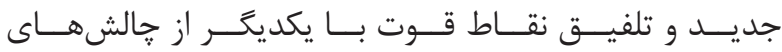

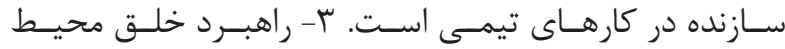

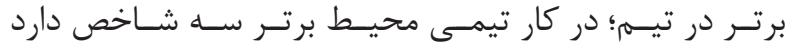

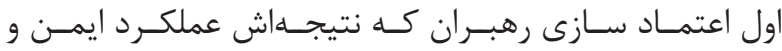

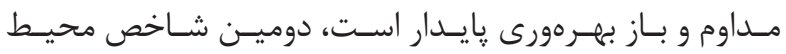

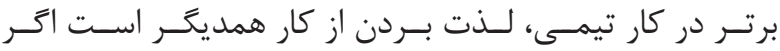

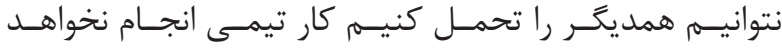

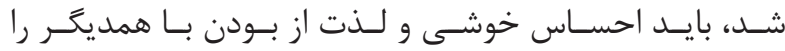

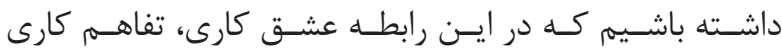

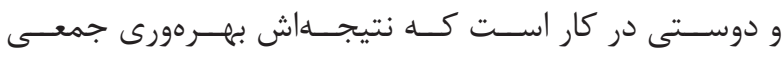

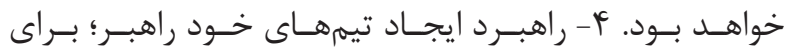

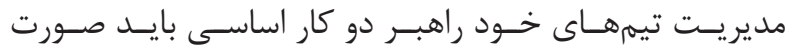

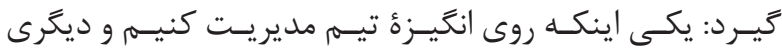

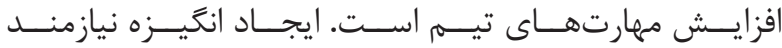

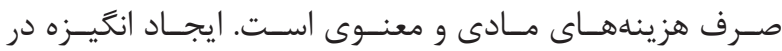

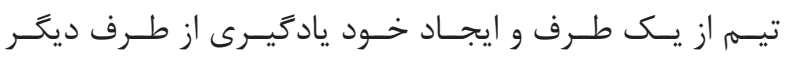

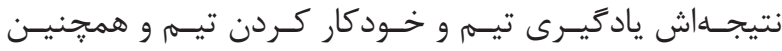

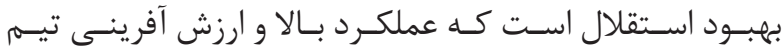

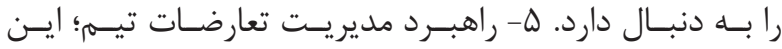

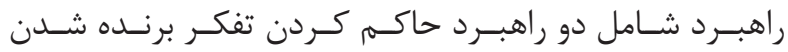

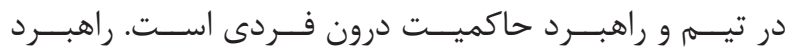

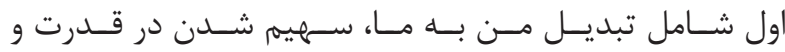

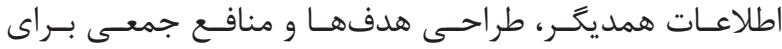

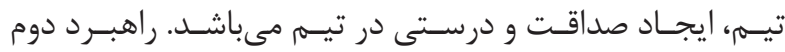

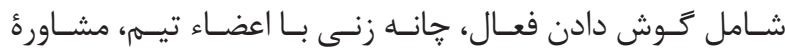

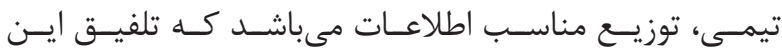

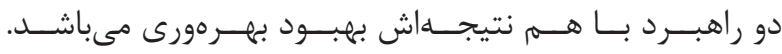

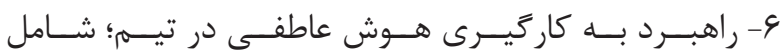

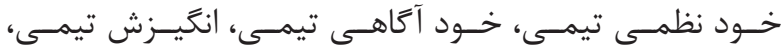

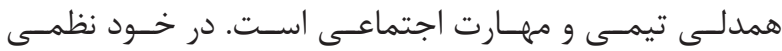

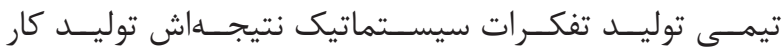

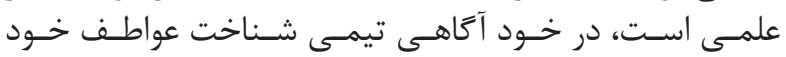

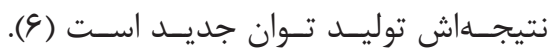
جايًَاه بهر هورى و تحول اقتصادى

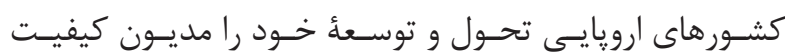

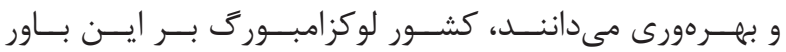

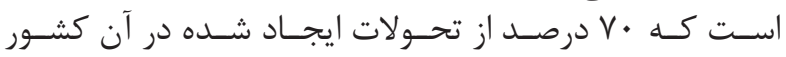




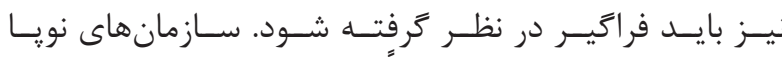

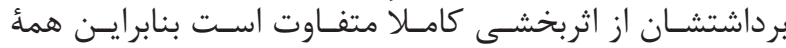

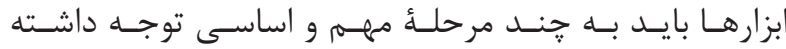

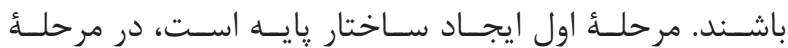

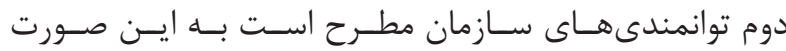

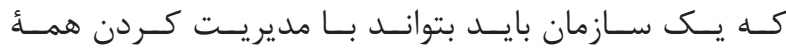

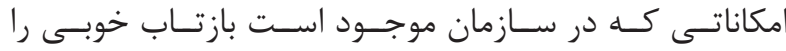

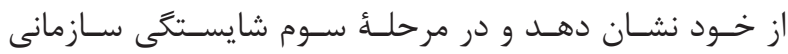

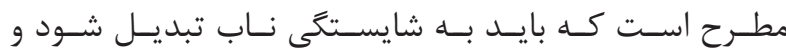

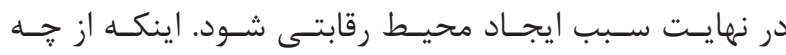

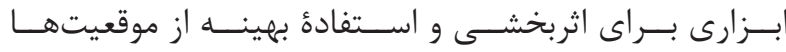

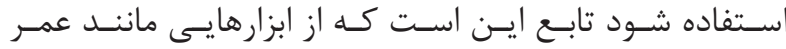

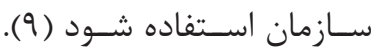

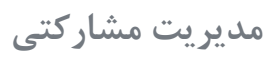

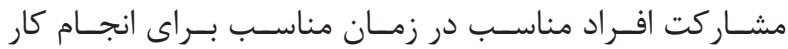

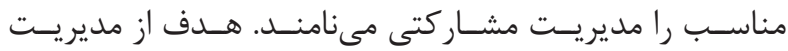

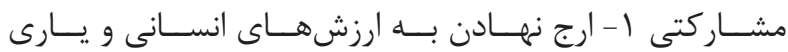

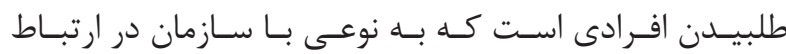

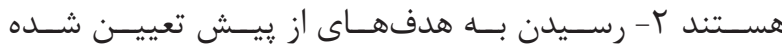

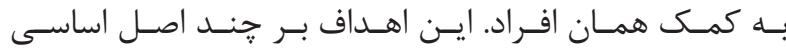

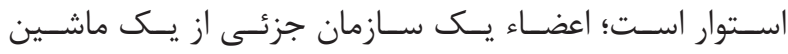

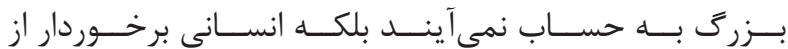

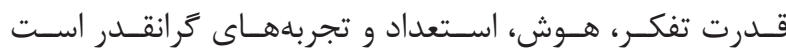

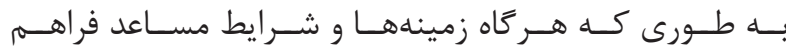

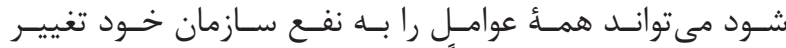

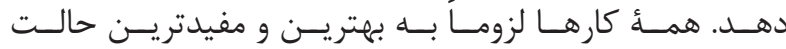

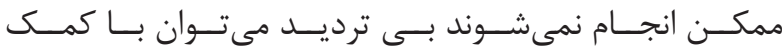

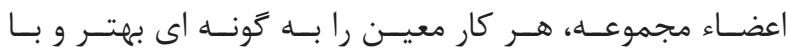

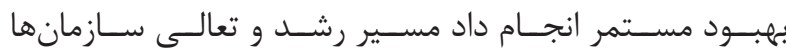

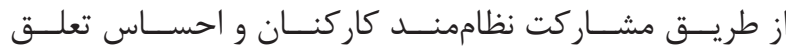

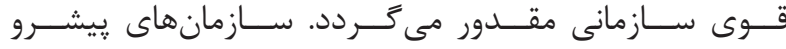

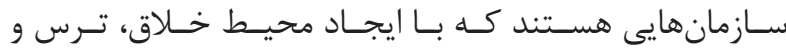

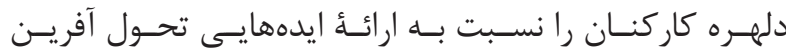

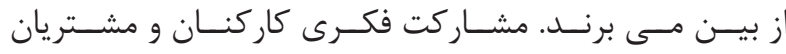

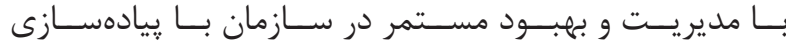

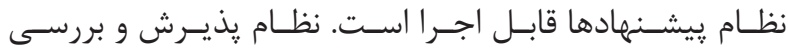

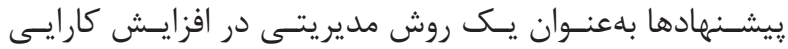

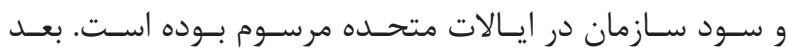

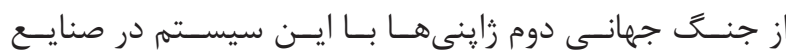

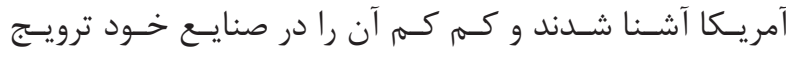

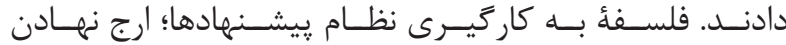

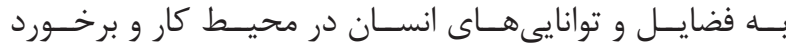

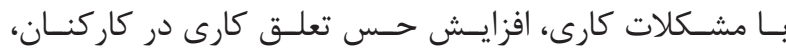

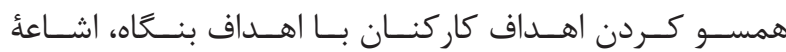

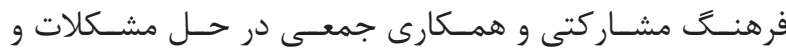

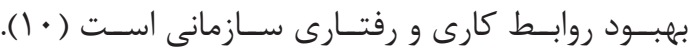

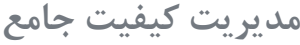

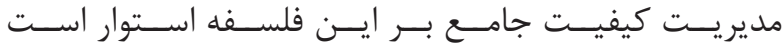

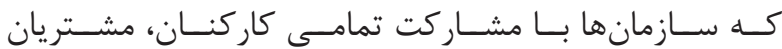

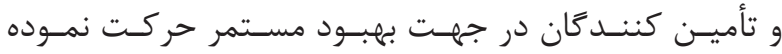

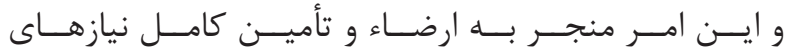

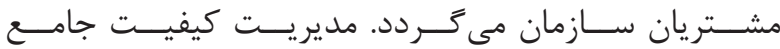

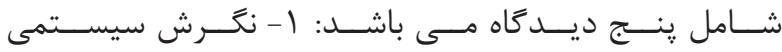

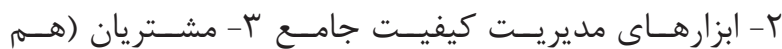

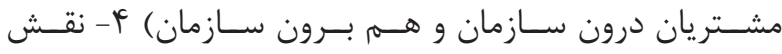

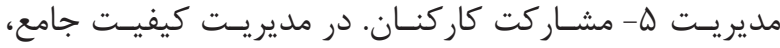

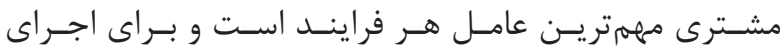

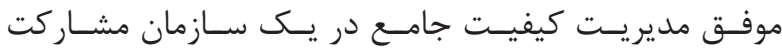

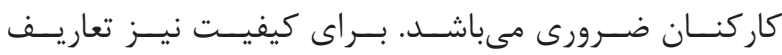

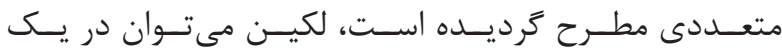

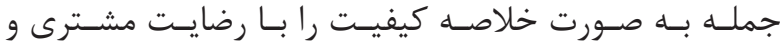

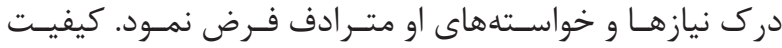

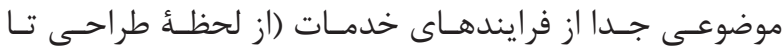

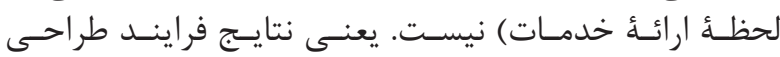

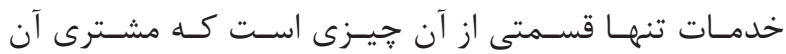

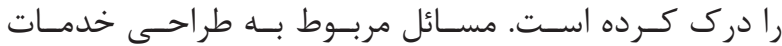

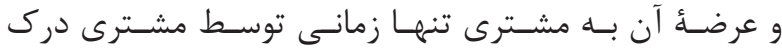

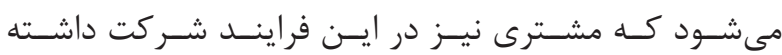

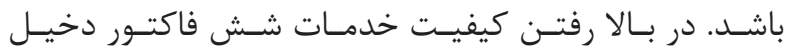

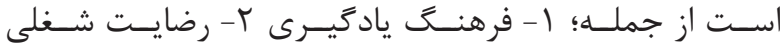

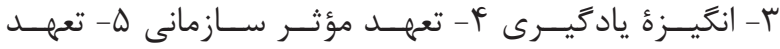

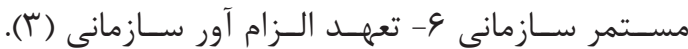
مديريت جامع از ديدَاه سازمانى

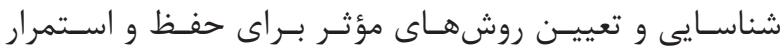

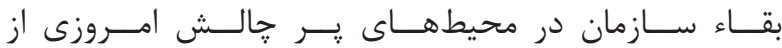

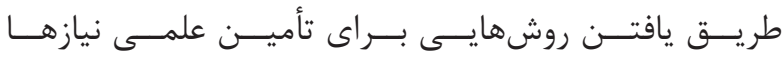

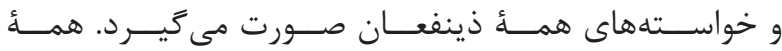

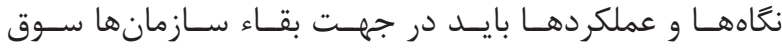

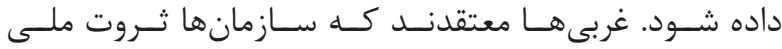

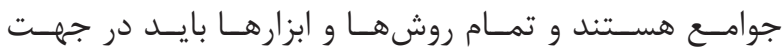

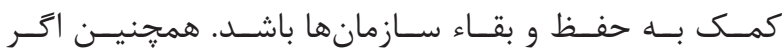

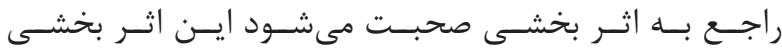

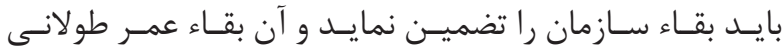

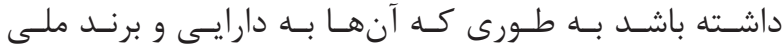

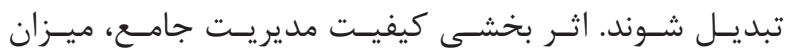

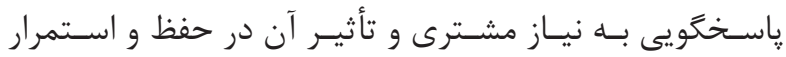

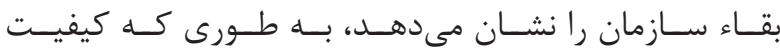

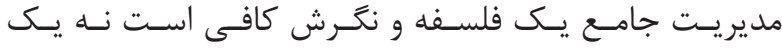

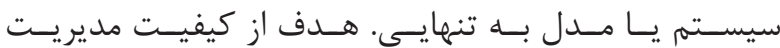

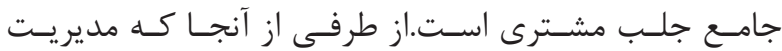

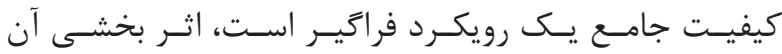




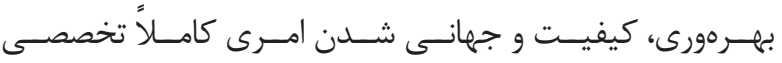

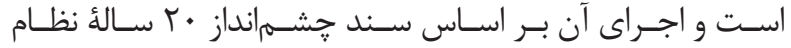

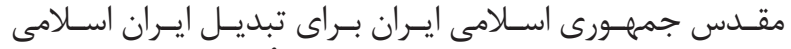

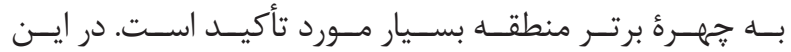

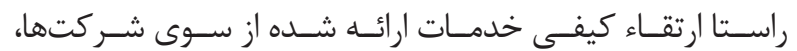

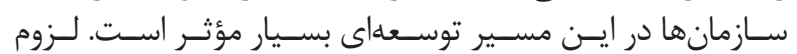

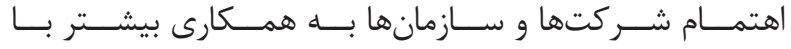

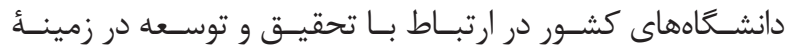

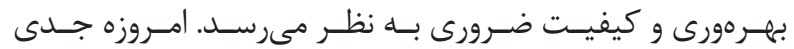

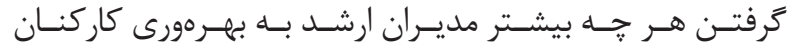

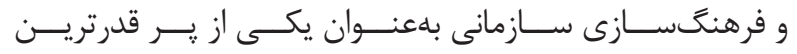

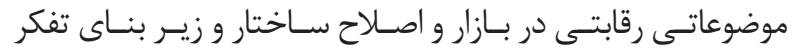

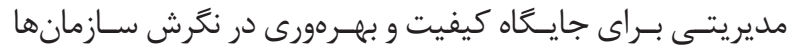

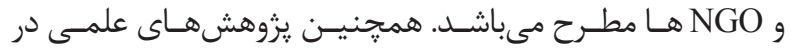

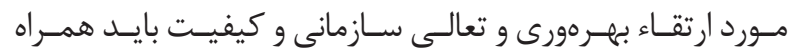

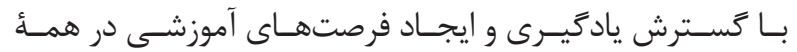

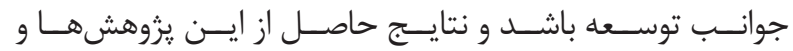

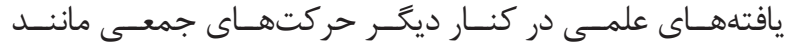

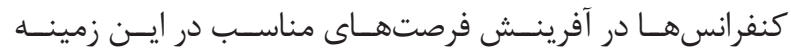

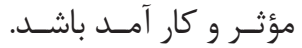

1. Brynjolfsson E, Yang S. Information technology and productivity : a review of the literature. Advances in Computers. 1996; 43: 179-214.

2. Berndt ER, Morrison, CJ. High-tech capital formation and economic performance in U.S. manufacturing industries: an exploratory analysis. Journal of Econometrics. 1995; 65(1): 9-43.

3. Bessant J, Caffyn S. High-involvement innovation through continuous improvement. Int J Technol Manag. 1997; 14(1): Doi: 10.1504/IJTM.1997.001705.

4. Sureshchandar GS, Chandrasekharan R, Kamalanabhan TJ. Customer perceptions of service quality: a critique. Total Quality Management. 2001; 12(1): 111-24.

5. Mowday RT, Steers RM, Porter LW. The measurement of organizational commitment. J Vocat Behav. 1979; 14(2): 224-47.

6. Bresnahan TF, Trajtenberg M. General purpose
نتيجه

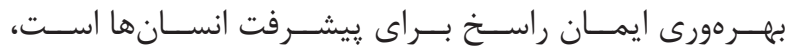

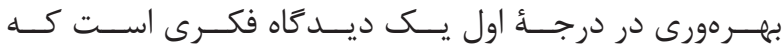

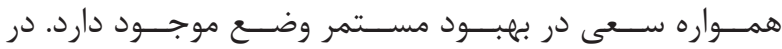

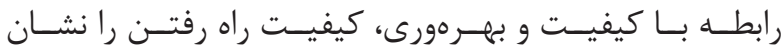

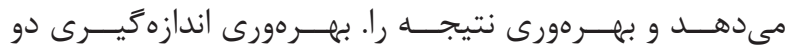

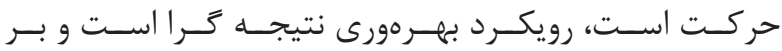

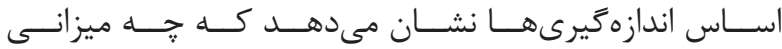

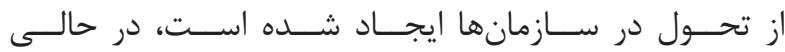

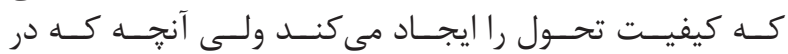

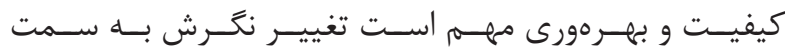

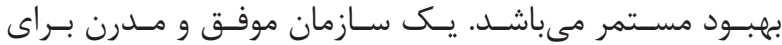

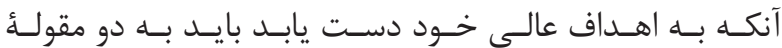

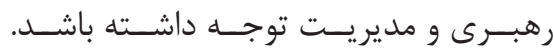

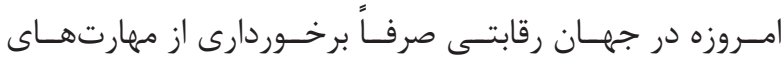

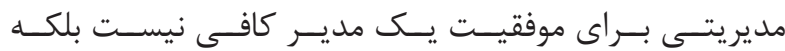

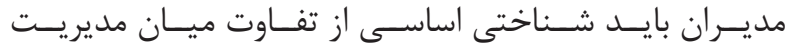

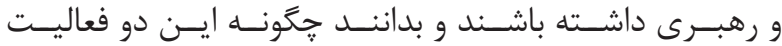

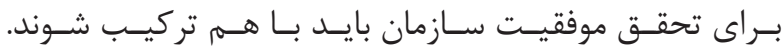

منابع

technologies and aggregate growth. Journal of Econometrics. 1995; 65(1): 83-108.

7. Meyer, JP, Herscovitch L. Commitment in the workplace: toward a general model. Human Resource Management Review. 2001; 11(3): 299-326.

8. Kunnanatt JT. Strategic change management experience of an Indian organization. Int $\mathrm{J}$ Manpow. 2007 ; 28(2): 175-92.

9. Zehir C, Gulen Ertosun O, Zehir S, Muceldilli B. Total quality management practices' effects on quality performance and innovative performance. Procedia Social and Behavioral Sciences. 2012; 41: 273-80.

10. Prajogo DI, Sohal AS. The relationship between organization strategy, total quality management (TQM), and organization performance-the mediating role of TQM. European Journal of Operational Research. 2006; 168(1): 35-50. 